\title{
The effects of thermal ageing on properties and microstructure of Al-6063 alloy
}

\begin{abstract}
The effect of thermal ageing on the properties and microstructure of $\mathrm{Al}-\mathrm{Mg}-\mathrm{Si}$ alloy was investigated. In this work, an extruded Al-6063 alloy samples were used as the main materials. In order to study the effect of thermal ageing, the alloy samples were solution treated at $530{ }^{\circ} \mathrm{C}$ and then quenched into water before artificially aged at elevated temperatures between 120 and $250{ }^{\circ} \mathrm{C}$. The ageing response and mechanical properties was monitored by Vickers hardness and tensile tests, respectively. The analysis of surface fracture and microstructure of peak aged alloy were carried out by means of scanning electron microscope (SEM) and transmission electron microscope (TEM), respectively. Result shows that the highest hardness value and tensile properties is gained by the alloy that aged at 120 ${ }^{\circ} \mathrm{C}$. It is found that increasing in hardness and strength values of the alloy are due to precipitates formation during thermal ageing. Fracture analysis on peak-aged condition indicates that the alloy having more ductility after thermal ageing. The result shows that the higher ageing temperature will lead to the higher ductility of the Al-6063 alloy, as a results the alloy's strength is reduced.
\end{abstract}

Keyword: Al-6063 alloy; Thermal ageing; Ageing response; Mechanical properties 